\title{
Feasibility of mixed nut challenges in children with suspicion of multiple tree nut allergies
}

\author{
Francine C Van Erp ${ }^{1 *}$, IL Kok ${ }^{2}$, MF Van Velzen ${ }^{1}$, AC Knulst ${ }^{3}$, CK Van der Ent ${ }^{1}$, Y Meijer ${ }^{1}$ \\ From Food Allergy and Anaphylaxis Meeting 2014 \\ Dublin, Ireland. 9-11 October 2014
}

\section{Background}

In children without any previous ingestion of nuts multiple sensitization to tree nuts is common. To minimize the risk of accidental reactions, those children are advised to exclude all nuts from their diets. Multiple food challenges would be needed to determine the presence of clinical relevant tree nut allergies, which is practically impossible. A pilot study to determine the feasibility of a mixed nut challenge in children with suspicion of multiple tree nut allergies was performed.

\section{Methods}

Children with previous negative hazelnut challenge and a lifelong nut free diet and / or sensitization to one or more tree nuts underwent an open mixed nut challenge. The mixture contained 6 gram of four or six tree nuts and applesauce. The challenge consisted of increasing portions of the mixture and was followed by the ingestion of each whole tree nut separately and when indicated a reintroduction schedule at home. Feasibility regarding safety, reactions during challenge, tolerance of the challenge material, satisfaction of the parents, reintroduction and dietary restrictions after challenge were evaluated.

\section{Results}

We included 18 children with a mean (SD) age of 10.2 (3.4) years. Mixed nut challenges were well accepted and conclusive in 16 (89\%) children and had a negative outcome in $11(61 \%)$ children. No life threatening reactions were observed, reactions were classified up to Sampson grade 2. Overall 12 children (67\%), including one child with inconclusive outcome, could reintroduce

\footnotetext{
'Department of Paediatric Pulmonology and Allergology, Wilhelmina Children's Hospital, University Medical Centre Utrecht, Utrecht, The Netherlands

Full list of author information is available at the end of the article
}

one or more tree nuts at home. Five children (28\%) could return to a diet without any nut related restrictions.

\section{Conclusion}

Mixed nut challenges are well accepted, safe and an efficient way to exclude multiple tree nut allergies especially in children with a lifelong nut free diet and low suspicion of allergy.

\section{Authors' details}

${ }^{1}$ Department of Paediatric Pulmonology and Allergology, Wilhelmina Children's Hospital, University Medical Centre Utrecht, Utrecht, The Netherlands. ${ }^{2}$ Internal Medicine and Dermatology, Department of Dietetics, University Medical Centre Utrecht, The Netherlands. ${ }^{3}$ Department of (Paediatric) Dermatology and Allergology, University Medical Centre Utrecht, Utrecht, The Netherlands.

Published: 30 March 2015

doi:10.1186/2045-7022-5-S3-P85

Cite this article as: Van Erp et al:: Feasibility of mixed nut challenges in children with suspicion of multiple tree nut allergies. Clinical and Translational Allergy 2015 5(Suppl 3):P85.

\section{Submit your next manuscript to BioMed Central and take full advantage of: \\ - Convenient online submission \\ - Thorough peer review \\ - No space constraints or color figure charges \\ - Immediate publication on acceptance \\ - Inclusion in PubMed, CAS, Scopus and Google Scholar \\ - Research which is freely available for redistribution \\ Submit your manuscript at www.biomedcentral.com/submit}

